\title{
Structure of interface in directionally solidified oxide eutectic systems
}

\author{
J. Echigoya
}

Department of Materials Science and Engineering, Iwate University

4-3-5, Ueda, Morioka 020-8551, Japan

\section{Abstract}

The morphology and orientation relationships between two phases was investigated in directionally solidified oxide eutectics of $\mathrm{ZrO}_{2}-\mathrm{MgO}, \mathrm{Al}_{2} \mathrm{O}_{3}-\mathrm{ZrO}_{2}\left(\mathrm{Y}_{2} \mathrm{O}_{3}\right)$ and $\mathrm{YIG}-\mathrm{Fe}_{3} \mathrm{O}_{4}$ systems using the high-resolution transmission electron microscopic technique. The growth morphology was determined by the volume fraction of the minor phase, the misfit between the two phases, and the growth direction of the eutectics. The interface included misfit dislocations and steps with an atomic height to accommodate the misfit at the interface. 
Introduction

In the past decades, directionally solidified eutectics have received considerable attention both as structural materials and for use in electronic devices ${ }^{1,2}$. Because of their high melting points, high strength to weight ratios at high temperatures, and resistance to oxidation, many ceramic eutectics are of interest as potential high temperature structural materials ${ }^{3-5}$. Since directionally solidified ceramic eutectics are free from transverse grain boundaries, they exhibit high rupture strength at high temperatures in comparison with sintered polycrystalline. Though single crystals are also free from grain boundaries, their tensile strength shows a rapid decrease with increasing temperature ${ }^{6}$. Several workers found a peculiar microstructure resulting from directional solidification, in which a YAG single crystal forms a network involving a single sapphire crystal ${ }^{7-9}$. This microstructure is quite different from that formed by directional solidification showing a fibrous or lamellar microstructure. Although the mechanical properties of a eutectic depend on the microstructure, an understanding of the crystallographic relationship and the interface structure between the phases is important to fundamental understanding as well as to realization of a good performance of the mechanical properties at high temperatures.

The present paper examines the crystallography and microstructure of directionally solidified oxide eutectics of $\mathrm{ZrO}_{2}-\mathrm{MgO}, \mathrm{Al}_{2} \mathrm{O}_{3}-\mathrm{ZrO}_{2}\left(\mathrm{Y}_{2} \mathrm{O}_{3}\right)$ and $\mathrm{YIG}-\mathrm{Fe}_{3} \mathrm{O}_{4}$ systems. The interface structure was intensively observed using high resolution electron microscopy. 
Experimental Procedure

The directional solidification of an oxide eutectic was accomplished by the Bridgman method using Mo crucibles. The growth rates used in the present experiments were 5 to $100 \mathrm{~mm} / \mathrm{h}$. Some sapphire base eutectics were directionally solidified at the growth rate of 10 to $90 \mathrm{~mm} / \mathrm{h}$ by the floating melting method using a single ellipsoid image furnace. The directionally solidified eutectic was cut and polished perpendicular and parallel to the growth direction. Thin foils were prepared by sectioning the directionally solidified eutectics. After being ground down to $0.1 \mathrm{~mm}$ with a diamond polisher, the section was ion-beam thinned in argon. The resulting foil was examined by JEOL-200CX and JEOL-ARM1250 transmission electron microscopes.

Results and Discussion

Growth morphology

The basic growth morphology of oxide eutectics can be generalized from the relative interfacial surface area per unit volume for the fibrous and lamellar structures. Figure 1 shows a schematic of the volume fraction dependence of interfacial area per unit volume ${ }^{10}$. Assuming an isotropic surface energy, to minimize the interfacial surface area in the development of a lamellar or fibrous microstructure, a hexagonal array of fibers is favored when the volume percent of the minor phase is less than $28 \%$. If the volume fraction of the minor phase is greater than $28 \%$, the morphology is 
lamellar. This situation is represented in Fig. 1. If substantial anisotropy in the surface energy exists, the lamellar structure can be stable at all volume fractions. In the present paper, mainly MgO- $\mathrm{ZrO}_{2}, \mathrm{Al}_{2} \mathrm{O}_{3}-\mathrm{ZrO}_{2}\left(\mathrm{Y}_{2} \mathrm{O}_{3}\right)$ and $\mathrm{YIG}-\mathrm{Fe}_{3} \mathrm{O}_{4}$ eutectics were investigated. These eutectics are located close to the transition point from fibrous to lamellar morphology.

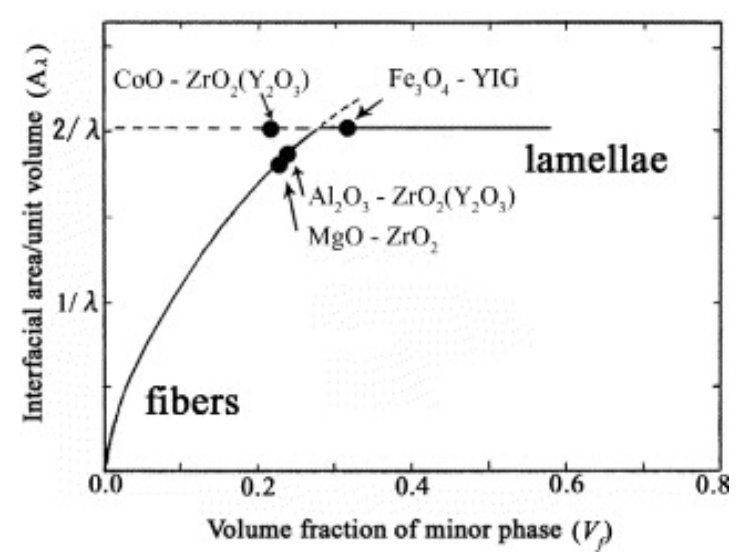

Fig.1. Schematic of volume fraction dependence of interfacial area per unit volume.

Figure 2 shows microstructures of transverse and longitudinal sections of a directionally solidified MgO- $\mathrm{ZrO}_{2}$ eutectic ${ }^{13,14}$. This indicates that the directional solidification of the $\mathrm{MgO}^{-} \mathrm{ZrO}_{2}$ eutectic forms a finely oriented microstructure of two phases with lamellar as well as the fibrous morphology. As seen from the Fig. 1, the $\mathrm{MgO}-\mathrm{ZrO}_{2}$ eutectic, in which the volume fraction of the $\mathrm{MgO}$ phase is $26 \%$, should have a fibrous morphology, if the surface energy is assumed to be isotropic. There are two reasons why both morphologies are observed in one sample, namely, the anisotropic interfacial energy and the growth direction. Figure 3 shows the electron diffraction pattern of the area of the directionally solidified $\mathrm{MgO}-\mathrm{ZrO}_{2}$ showing the fibrous morphology (a) and that of the area showing 
the lamellar microstructure (b). This figure revealed growth directions $[011] \mathrm{z} / /[011] \mathrm{m}$ and plane

(hkl)z//(hkl)m for the fibrous morphology and growth directions [001]z//[011]m and interface (010)z//(111)m for the lamellar morphology, where $\mathrm{m}$ and $\mathrm{z}$ indicate $\mathrm{MgO}$ and cubic $\mathrm{ZrO}_{2}$ phases, respectively. That the orientation relationships between the two phases are different for the different morphologies suggests that a low energy interface exists for the particular interface of (010)z//(111)m. The lamellar morphology is observed only when the growth direction includes the low energy interface of $(010) \mathrm{z} / /(111) \mathrm{m}$. When the growth direction is different from the above condition, the growth morphology should be fibrous. It should be pointed out that the growth directions of lamellar and fibrous morphologies were different, i.e., the directionally solidified eutectic is a polycrystalline including grain boundaries even though it did not form a cell structure. Only lamellar morphology could be observed in the sample of the directionally solidified $\mathrm{CoO}-\mathrm{ZrO}_{2}$ and $\mathrm{CoO}-\mathrm{ZrO}_{2}\left(\mathrm{Y}_{2} \mathrm{O}_{3}\right)$ eutectics, even when the volume fraction of the minor phase was $23 \%{ }^{10,11}$. This is a typical example of the growth direction including a low energy interface of (010)z//(111)c.

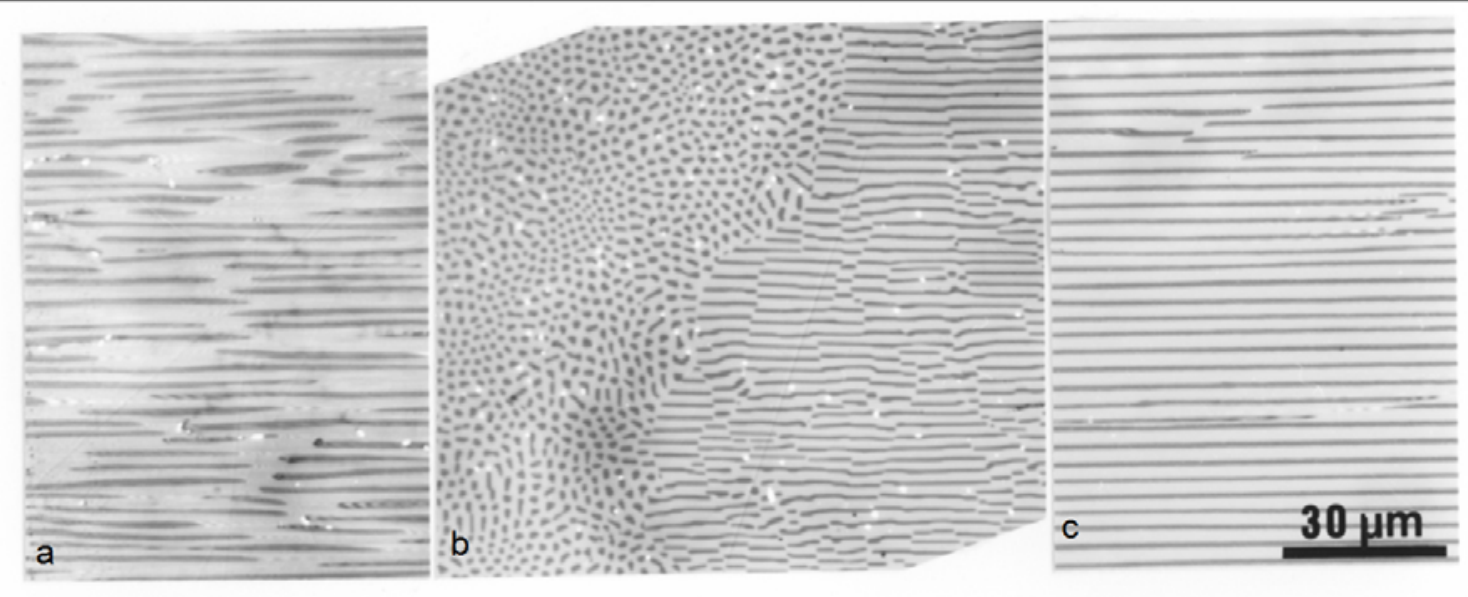

Fig.2. Microstructures of transverse and longitudinal sections of directionally solidified $\mathrm{MgO}^{-}$ $\mathrm{ZrO}_{2}$ eutectic. (a) shows the transverse section, and (b) and (c) are the longitudinal sections of the area showing the fibrous morphology and of the lamellar morphology, respectively. 

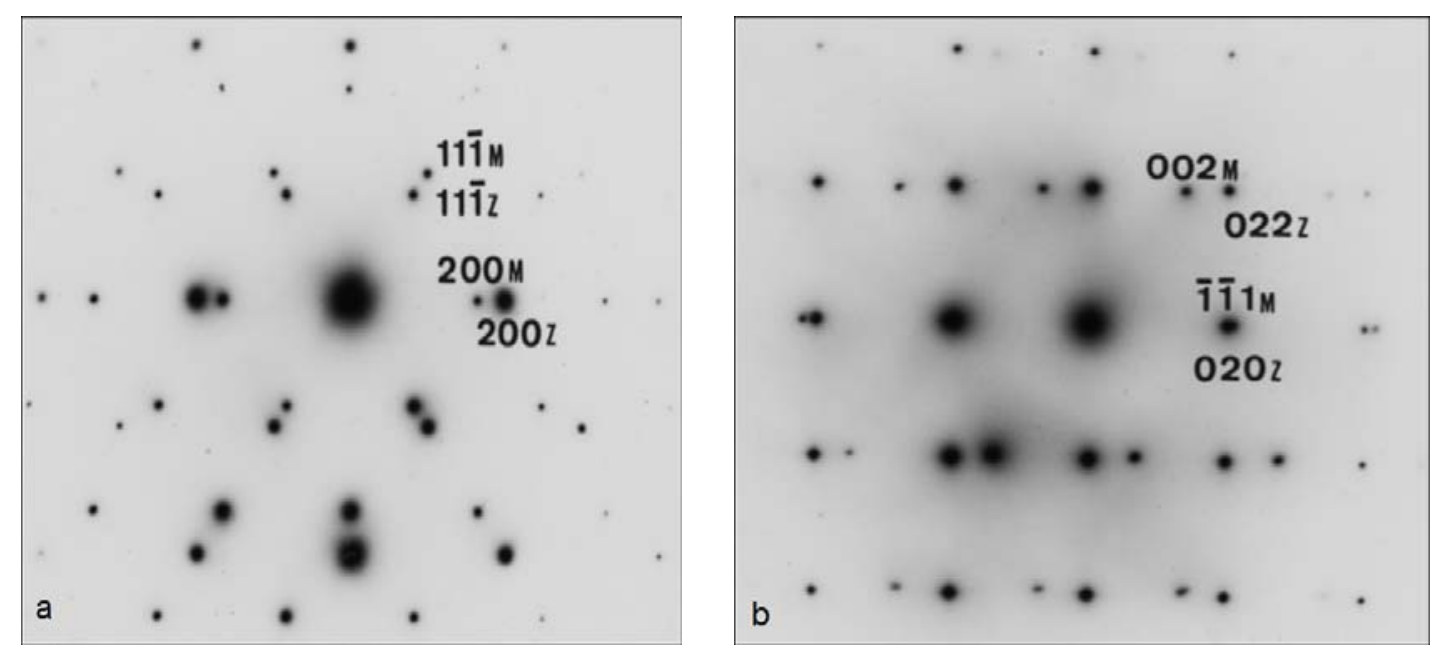

Fig.3. Electron diffraction pattern of the area showing the fibrous morphology (a) and the area showing the lamellar morphology (b) of directionally solidified $\mathrm{MgO}-\mathrm{ZrO}_{2}$.

Figure 4 is an electron micrograph of directionally solidified $\mathrm{Al}_{2} \mathrm{O}_{3}-\mathrm{ZrO}_{2}\left(3 \mathrm{~mol} \% \mathrm{Y}_{2} \mathrm{O}_{3}\right)$ grown on a (102) sapphire single crystal ${ }^{15}$. The morphology is fibrous and the orientation relationship is as follows: Growth direction perpendicular to (102)a//(001)z(110)a//(100)z, (012)a//(110)z.
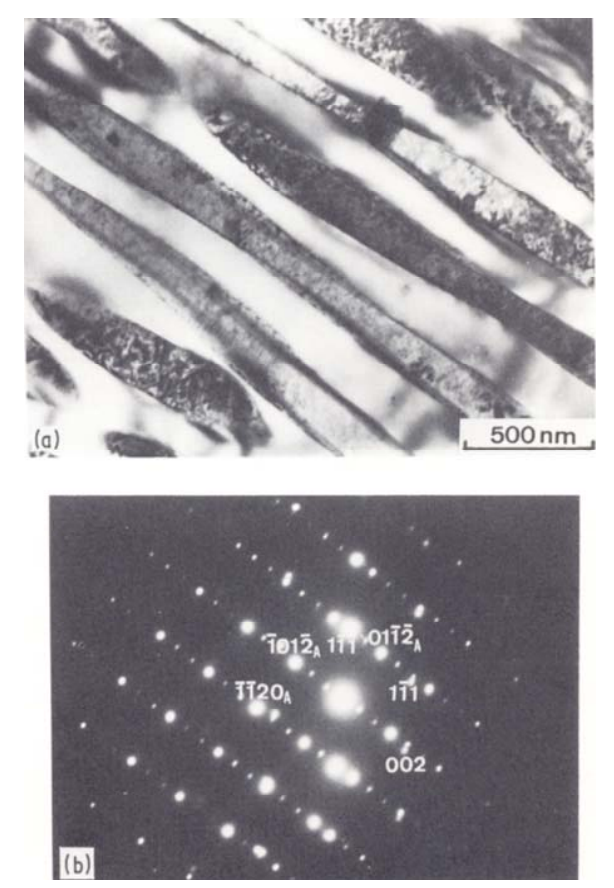

Fig.4. Electron micrograph of directionally solidified Al2O3- $\mathrm{ZrO}_{2}\left(3 \mathrm{~mol} \% \mathrm{Y}_{2} \mathrm{O}_{3}\right)$ grown on a (102) sapphire single crystal 
The microstructure has a wavy interface and the minor phase of the tetragonal/cubic $\mathrm{ZrO}_{2}$ is not well

aligned. The growth morphology of $\mathrm{Al}_{2} \mathrm{O}_{3}-\mathrm{ZrO}_{2}$ eutectic grown on a (0001) sapphire single crystal was indicated to have a fibrous structure with cells ${ }^{16,17}$. The orientation relationship was fundamentally (001)a//(001)z, (100)a//(010)z, and (110)a//(100)z, though the plane perpendicular to the growth direction of [001]z was distributed from (001) to (101)a.

Figure 5(a) and (b) show an optical micrograph and an electron micrograph of a directionally solidified $\mathrm{Fe}_{3} \mathrm{O}_{4}$ - $\mathrm{YIG}\left(\mathrm{Y}_{3} \mathrm{Fe}_{5} \mathrm{O}_{12}\right)$ eutectic ${ }^{18}$. Since the volume fraction of the minor phase in the system is more than $30 \%$, the growth morphology is a plate structure, i.e., a structure with broken and deformed lamellae. This structure is known as the Chinese script morphology, such morphology being formed by the connection of the plates with each other. The electron micrograph indicates a wavy interface. The orientation relationship between the two phases was obtained by electron diffraction patterns and determined as being (111)f//(121)y and (011)f//(513)y and (211)f//(311)y, where $\mathrm{f}$ and $\mathrm{y}$ indicate $\mathrm{Fe}_{3} \mathrm{O}_{4}$ and $\mathrm{YIG}$ phases, respectively, as shown in Fig. 6 . The two phases of the eutectics showed the same orientation relationship throughout the present experiment. Figure 6 reveals that reflections of the second row are completely coincident with each other. Since the lattice spacing which gives rise to the coincident reflections is almost the same throughout the specimen, the planes with small misfits exist perpendicular 
to the growth direction. This is one of the reasons that the interface plane was wavy in this

system.
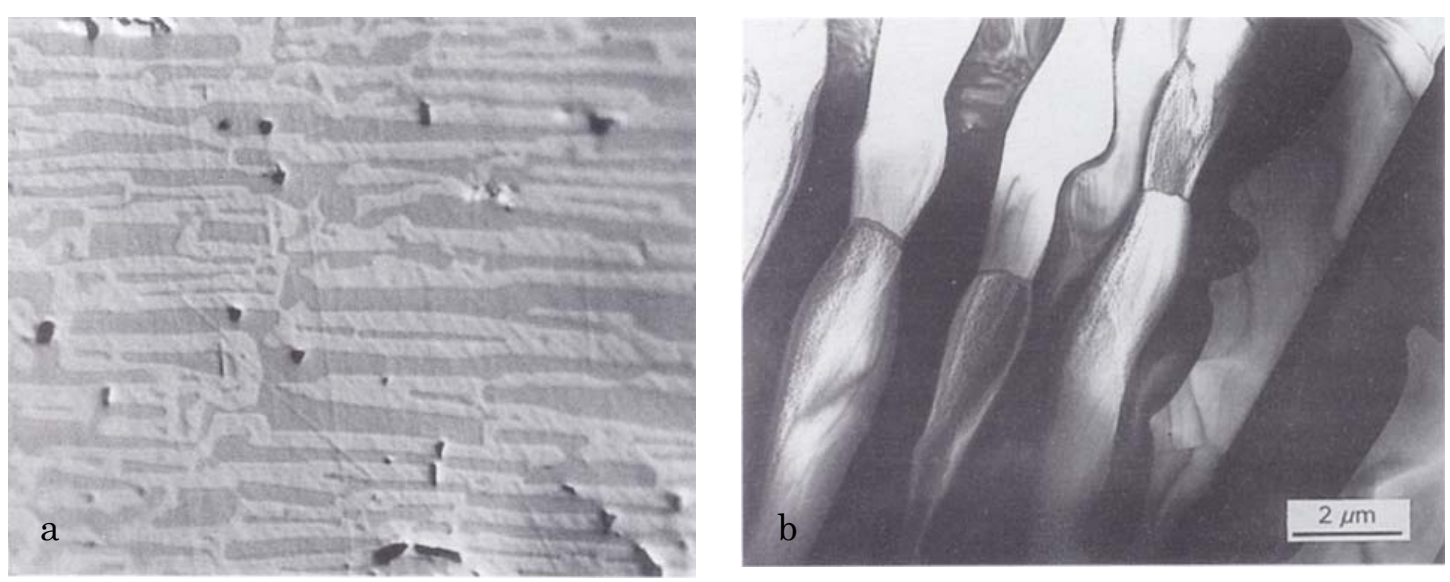

Fig.5. Optical micrograph (a) and electron micrograph (b) of directionally solidified $\mathrm{Fe}_{3} \mathrm{O}_{4}-\mathrm{YIG}\left(\mathrm{Y}_{3} \mathrm{Fe}_{5} \mathrm{O}_{12}\right)$ eutectic.
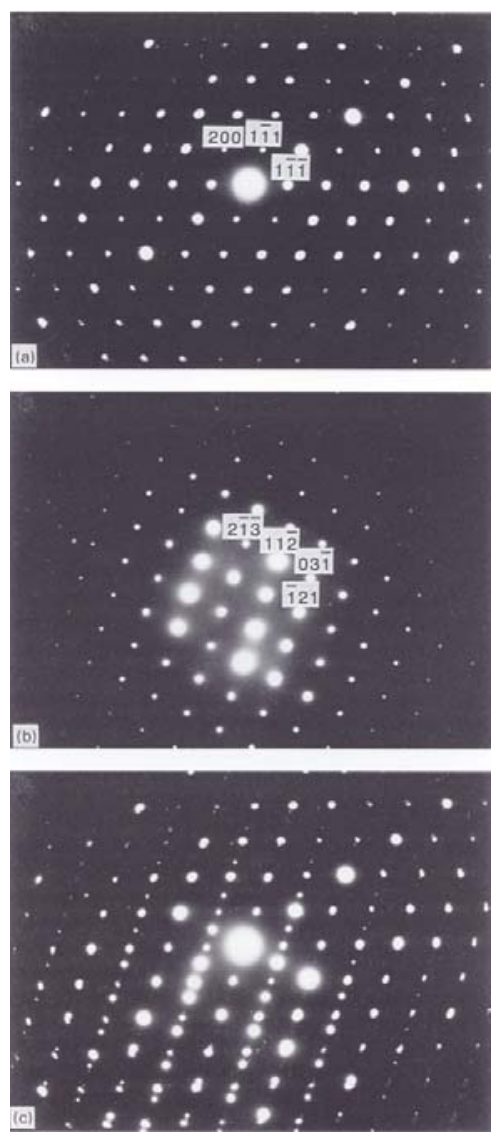

Fig.6. Electron diffraction patterns of directionally solidified $\mathrm{Fe}_{3} \mathrm{O}_{4}$-YIG eutectic: (a) $\mathrm{Fe}_{3} \mathrm{O}_{4}$, (b) $\mathrm{YIG}$ phase and (c) an interface. 
Interface structure

Figure 7 shows a high-resolution electron micrograph of the fibrous interface in the directionally solidified $\mathrm{MgO}-\mathrm{ZrO}_{2}$ eutectic $^{19}$. The interface was faceted and formed by (100), (110) and (111) planes. Because of the large misfit of $17 \%$ between cubic $\mathrm{ZrO}_{2}$ and $\mathrm{MgO}$ in the case of the cube/cube relationship, the misfit dislocations were introduced periodically at intervals of $1.7 \mathrm{~nm}$. The lamellar interface, which was formed by (001)z//(111)m planes, has an extremely good atomic fit. The sequence of the atomic plane parallel to the interface is metal/oxygen/metal/oxygen/metal/oxygen stacking across the interface as shown schematically in Fig. 8. Figure 9 shows a high-resolution electron micrograph of the lamellar interface observed in the directionally solidified $\mathrm{MgO}-\mathrm{ZrO}_{2}$ eutectic. Careful observation reveals a stepped structure at the interface. The height of a step is one atomic layer of $0.25 \mathrm{~nm}$ and the spacing between steps is $3.75 \mathrm{~nm}$. Figure 10 shows the superimposed oxygen lattices of $\mathrm{MgO}$ and cubic $\mathrm{ZrO}_{2}$ phases seen from the growth direction. This indicates that atomic steps are responsible for the increase of the area of good fit. This means that a misfit of about $1.9 \%$ of atomic distance between the [211]m and [100]z directions, which is along the interface, is accommodated by steps with an atomic height of one. The periodic introduction of steps leads to the declination of the interface plane from the exact (111)m and (100)z planes. The stepped structure at the interface was also observed in the lamellar interface of the directionally solidified $\mathrm{CoO}-\mathrm{ZrO}_{2}\left(\mathrm{Y}_{2} \mathrm{O}_{3}\right)$ and $\mathrm{NiO}-\mathrm{Gd}_{2} \mathrm{O}_{3}$ eutectics ${ }^{14,20}$. This 
stepped structure with an atomic height of one in the $\mathrm{MgO}-\mathrm{ZrO}_{2}$ eutectic is the first such observation

in directionally solidified eutectics to accommodate a misfit at the interface. The misfit dislocations and steps may play important roles as sinks or sources of vacancies and as a nucleation site of dislocations in the case of high temperature deformation.
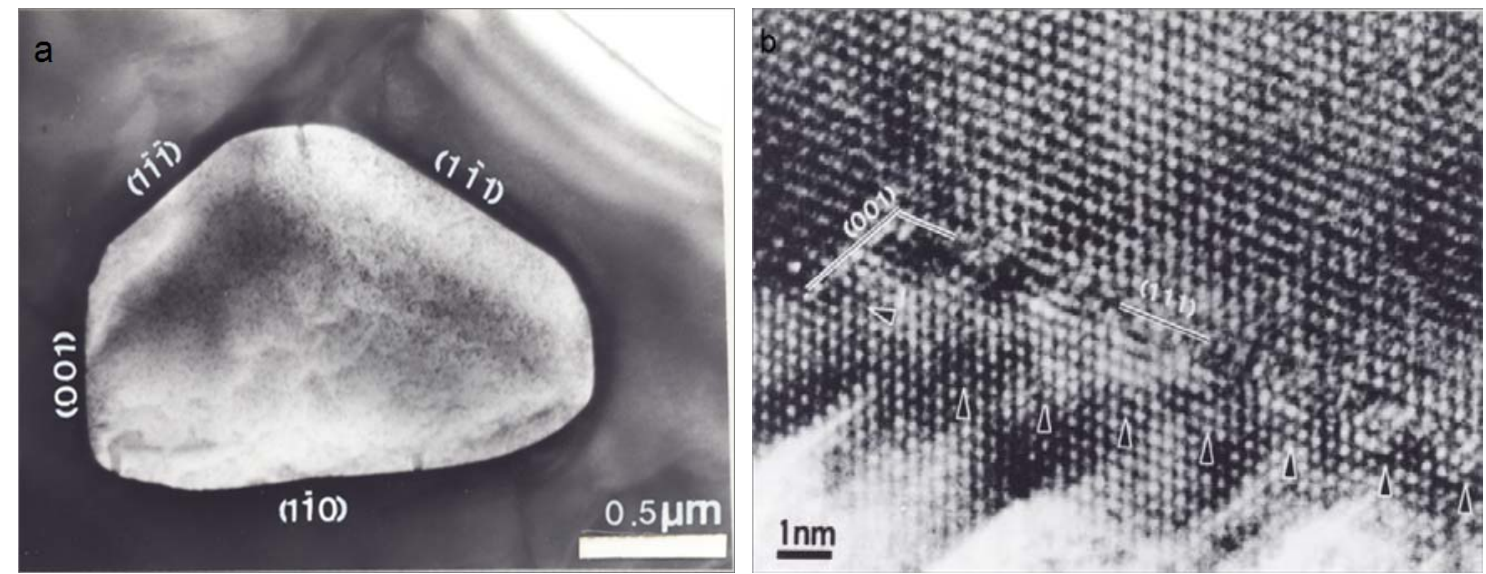

Fig.7. High-resolution electron micrograph of the fibrous interface in the directionally solidified $\mathrm{ZrO}_{2}-\mathrm{MgO}$ eutectic.

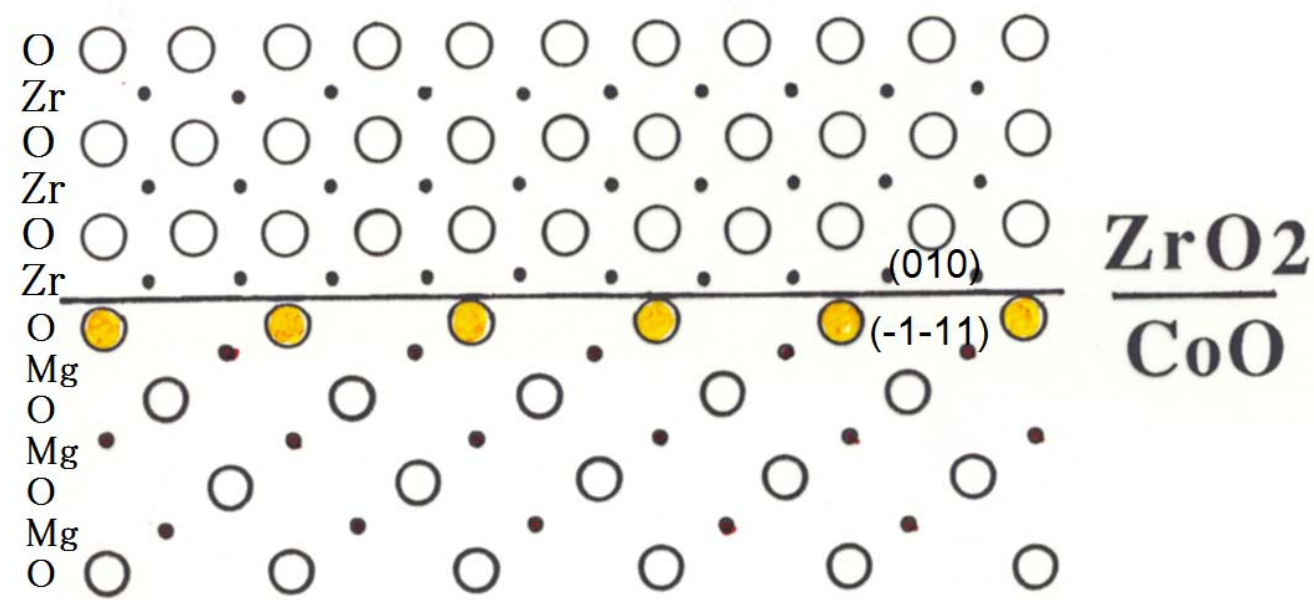

Fig.8. Schematic drawing of lamellar interface, which was formed by $(001) \mathrm{z} / /(111) \mathrm{m}$ planes, showing the sequence of atomic plane parallel to the interface 


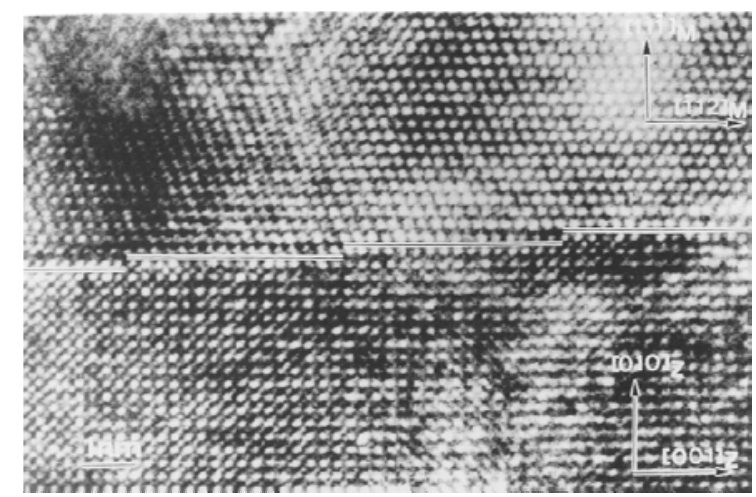

Fig. 9 .High-resolution electron micrograph of the lamellar interface observed in the directionally solidified $\mathrm{MgO}-\mathrm{ZrO}_{2}$ eutectic.

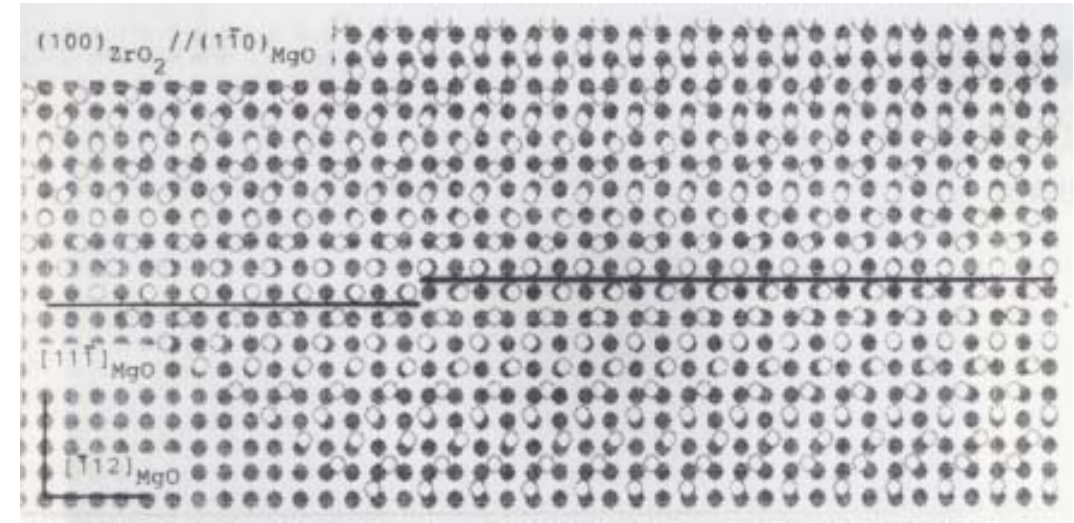

Fig.10. Superimposed oxygen lattices of $\mathrm{MgO}$ and cubic $\mathrm{ZrO}_{2}$ phases seen from the growth direction.

Figure 11 shows a high resolution lattice image of the interface of $\mathrm{Fe}_{3} \mathrm{O}_{4}-\mathrm{YIG}$ eutectic seen from the $<011>\mathrm{f} / /<135>\mathrm{y}$ directions. The interface was wavy and consisted of low indexed planes of $\{111\}$ and $\{311\} \mathrm{Fe}_{3} \mathrm{O}_{4}$ planes. The continuity of the lattice planes across the interface was extremely good. Figure 12 shows a high-resolution electron micrograph of the directionally solidified eutectic. The beam direction, i.e., the growth direction, is [112]f//[113]y and (111)f is parallel to (112)y. This relationship is coincident with the relationship mentioned above, which means that the 
orientation relationships between $\mathrm{Fe}_{3} \mathrm{O}_{4}$ and YIG were retained even when the growth direction changed. The lattice fringe image of both phases was clear and well-defined from grain to interface as seen in Fig. 11. On the other hand, as shown in Fig. 12, the lattice fringe image showing the ordered structures of YIG and $\mathrm{Fe}_{3} \mathrm{O}_{4}$ became diffuse near the interface within two to three atomic layers when an interface was not formed from the low-index plane. Because the ordered YIG and $\mathrm{Fe}_{3} \mathrm{O}_{4}$ structures have a complicated atomic arrangement with a large unit cell, disorder of the ordered structure seems to occur during solidification. The misfit between (111)f and (112)y planes is $4.2 \%$.

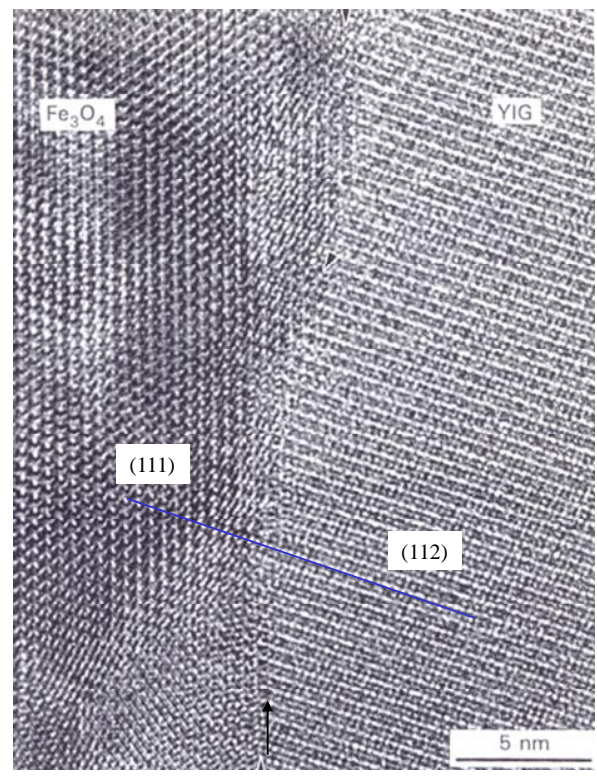

Fig.11. High-resolution electron micrograph of the directionally solidified $\mathrm{Fe}_{3} \mathrm{O}_{4^{-}}$ YIG eutectic 


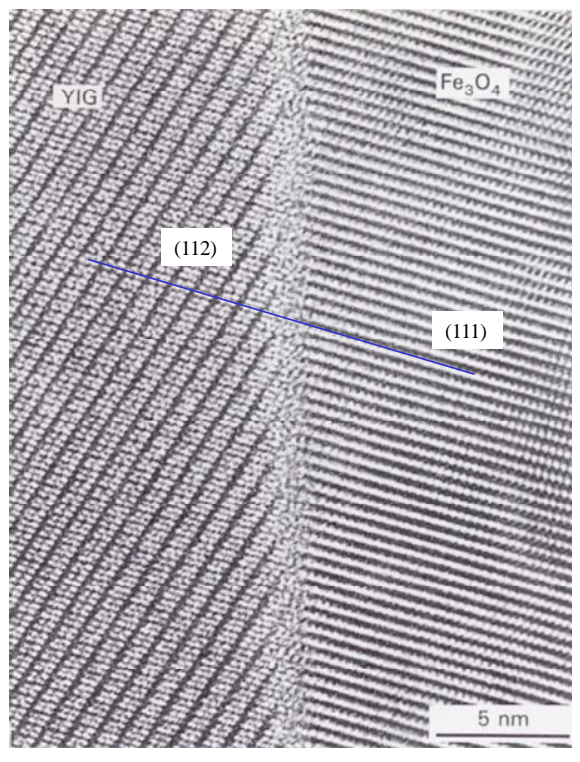

Fig.12. Lattice fringe image of the directionally solidified $\mathrm{Fe}_{3} \mathrm{O}_{4}$-YIG eutectic showing diffuseness of atomic ordering of YIG near the interface. Growth direction was [112]f//[113]y.

Possibility of the application of eutectics to devices

The $\mathrm{BaTiO}_{3}-\mathrm{CoFe}_{2} \mathrm{O}_{4}$ eutectic system is an interesting system because $\mathrm{BaTiO}_{3}$ and $\mathrm{CoFe}_{2} \mathrm{O}_{4}$ are materials with large electric striction and magneto striction ${ }^{21}$. Application of this system can be achieved by the combination of magnetic and electric properties through strain. The interface in the directionally solidified $\mathrm{BaTiO}_{3}-\mathrm{CoFe}_{2} \mathrm{O}_{4}$ eutectic was bonded directly, but the electrical resistivity of the eutectic was too small to apply to a device due to the dissolution of a small amount of solute ${ }^{21}$. If the eutectic system is to be applied to devices, it will be necessary to select properties which are non-sensitive to a small amount of solute, because any materials, even eutectic components, are dissolved solute. 
Structure similar to that of directionally solidified eutectics

Generally, the eutectic structure has two morphologies, i.e., a fibrous and a lamellar microstructure.

Similar structures are obtained by eutectoid decomposition and phase decomposition during deposition. Figure 13 shows an electron micrograph of 11 mol\%MgO- $\mathrm{ZrO}_{2}$ aged at $1573 \mathrm{~K}$ for 432 $\mathrm{ks}^{22}$. An $11 \mathrm{~mol} \% \mathrm{MgO}-\mathrm{ZrO}_{2}$ used for the present experiment was sintered at $1973 \mathrm{~K}$ in air to form a single phase cubic $\mathrm{ZrO}_{2}$ solid solution and then air-quenched at the rate of about 300 degree/s. This eutectoid consists of $\mathrm{MgO}$ rods in the monoclinic $\mathrm{ZrO}_{2}$ phase elongated along 100 monoclinic $\mathrm{ZrO}_{2}$ direction. The orientation relationship indicated that the interface between $\mathrm{MgO}$ and $\mathrm{ZrO}_{2}$ consisted of (111)m//(100)z, which was the same as the relationship which appeared in the directionally solidified eutectic. Because the decomposition temperature is lower than the temperature of the eutectic reaction, the structure formed by the eutectoid is much finer than that of the eutectic.

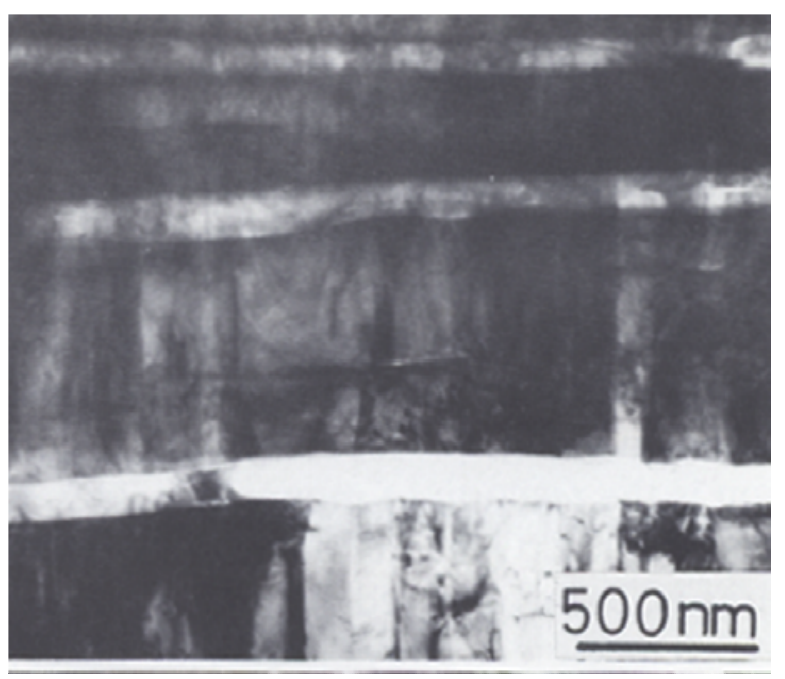

Fig. 13. Electron micrograph of $11 \mathrm{~mol} \% \mathrm{MgO}-\mathrm{ZrO}_{2}$ aged at $1573 \mathrm{~K}$ for $432 \mathrm{ks}$. 
Figure 14 shows a bright field image of a plan-view of a Co ferrite film sputter-deposited at a substrate temperature of $670 \mathrm{~K}^{23}$. The film consists of two phases, indicating the presence of precipitates of rectangular shape in the Co ferrite matrix. Electron diffractions and an electron micrograph of a cross-sectional view reveal that the precipitates are Co and are elongated in a filament-like fashion in the direction of growth. This result indicates the possibility that the formation by deposition of such structure is equivalent to the directional solidification.

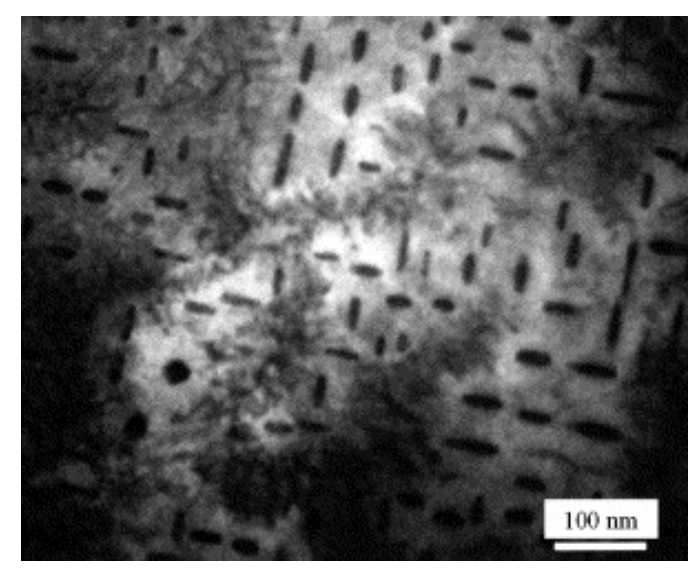

Fig. 14. Bright field image of a plan-view of a Co ferrite film sputter-deposited at a substrate temperature of $670 \mathrm{~K}$

\section{Conclusion}

The morphology and orientation relationships between two phases were investigated in directionally solidified oxide eutectic systems using the high-resolution transmission electron microscopic technique. The morphology was determined by the volume fraction of the minor phase, the misfit at the interface, and the growth direction of the eutectics. The interface included misfit dislocations and steps with an atomic height to accommodate the misfit at the interface. 


\section{References}

1. Ashbrook, R. L., Directionally solidified ceramic eutectics, J. Am. Ceram. Soc., 1977, 60, 428-435.

2. Stubican, V. S. and Bradt, R. C., Eutectic solidification in ceramic systems, Ann. Rev. Mater. Sci., 1981, 11, 267-297.

3. Waku, Y., Nakagawa, N., Wakamoto, T., Ohtsubo, H., Shimizu, K., and Kohtoku, Y., A ductile ceramic eutectic composite with high strength at 1873 K, Nature, 1997, 389, 49-52.

4. Waku, Y., Nakagawa, N., Wakamoto, T., Ohtsubo, H., Shimizu, K., and Kohtoku, Y., High temperature strength and thermal stability of a unidirectionally solidified $\mathrm{Al}_{2} \mathrm{O}_{3} / \mathrm{YAG}$ eutectic composite, J. Mater. Sci., 1998, 33, 1217-1225.

5. Martinez Fernandez, J., Sayir, A. and Farmer, S. C., High temperature creep deformation of directionally solidified $\mathrm{Al}_{2} \mathrm{O}_{3} / \mathrm{Er}_{3} \mathrm{Al}_{5} \mathrm{O}_{12}$, Acta Mater., 2003, 51, 1705-1720.

6. Kingery, W. D., Bowen, H. K. and Uhlmann, D. R., Introduction to Ceramics, $2^{\text {nd }}$ Ed.John Wiley \& Sons, New York 1976.

7. Mah, T., Parthasarathy, T. A., Petry, M. D. and Matson, L. E., Processing, microstructure and properties of $\mathrm{Al}_{2} \mathrm{O}_{3}$-YAG eutectic fibers, Ceramic Engineering and Science Proceedings, 1993, 14, 622-638.

8. Farmer, S. C., Sayir, A, Dickerson, P. O. and Draper, S. L., Microstructural stability and strength 
retention in directionally solidified $\mathrm{Al}_{2} \mathrm{O}_{3}$-YAG eutectic fibers, Ceramic Engineering and Science Proceedings, 1995, 16, 969-976.

9. Waku, Y., Ohtsubo, H. Nakagawa, H. and Kohtoku, Y., Sapphire matrix composites reinforced with single crystal YAG phases, J. Mater. Sci., 1996, 31, 4663-4670.

10. Minford, W. J., Bradt, R. C. and Stubican, V. S., Crystallography and microstructure of directionally solidified oxide eutectics, J. Am. Ceram. Soc., 1979, 62, 154-157.

11. Echigoya, J., Hayashi, S., Sasaki, K. and Suto, H., Microstructure of directionally solidified MgO- $\mathrm{ZrO}_{2}$ eutectic, J. Japan, Inst. Metals, 1984, 48, 430-434.

12. Echigoya, J., Suto, H. and Hayashi, S., Growth morphology and orientation relationships in directionally solidified MgO- $\mathrm{ZrO}_{2}$ eutectic, Trans. JIM, 1985, 26, 895-900.

13. Echigoya, J. and Hayashi, S., Directional solidification of $\mathrm{CoO}-\mathrm{ZrO}_{2}$ eutectics, J. Crystal Growth, 1993, 129, 699-705.

14. Echigoya, J. and Hayashi, S., Interface structure of directionally solidified of $\mathrm{CoO}-\mathrm{ZrO}_{2}\left(\mathrm{Y}_{2} \mathrm{O}_{3}\right)$ eutectic, Ceramic Transactions, 1994, 44, 445-453.

15. Echigoya, J., Takabayashi, Y., Suto, H. and Ishigame, M., Structure and crystallography of directionally solidified $\mathrm{Al}_{2} \mathrm{O}_{3}-\mathrm{ZrO}_{2}-\mathrm{Y}_{2} \mathrm{O}_{3}$ eutectic by the floating zone melting method, J. Mater. Sci. Letters, 1986), 5, 150-152.

16. Echigoya, J., Takabayashi, Y., Sasaki, K., Hayashi, S. and Suto, H., Solidification microstructure 
of $\mathrm{Y}_{2} \mathrm{O}_{3}$ added $\mathrm{Al}_{2} \mathrm{O}_{3}-\mathrm{ZrO}_{2}$ eutectic, Trans. JIM, (1986) 27, 102-107.

17. Mazerolles, L., Michel, D. and Portier, R., Microstructure and mechanical behaviour of Al2O3-ZrO ${ }_{2}\left(\mathrm{Y}_{2} \mathrm{O}_{3}\right)$ oriented eutectics, J Physique, C1, 1986, 47, 335-339.

18. Echigoya, J., Hayashi, S. and Sasaki, K., Directional solidification and interface structure of $\mathrm{Fe}_{3} \mathrm{O}_{4}$-YIG eutectic, J. Mater. Sci., 1996, 31, 3965-3969.

19. Echigoya, J. and Suto, H., Structure of interphase interface and solute segregation in

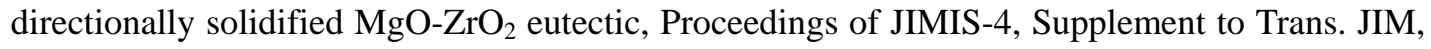
1986, 213-220.

20. Echigoya, J., Dhalenne, G. and Revcolevschi, A., T.E.M. study of interfaces of directionally solidified NiO- $\mathrm{Gd}_{2} \mathrm{O}_{3}$ eutectic structures, Science of Ceramics, 14, 437-442.

21. Echigoya, J., Hayashi, S. and Obi, Y., Directional solidification and interface structure of $\mathrm{BaTiO}_{3}-\mathrm{CoFe}_{2} \mathrm{O}_{4}$ eutectic, J. Mater. Sci., 2000, 35, 5587-5591.

22. Echigoya, J., Sasai, K. and Suto, H., Microstructural change of $11 \mathrm{~mol} \% \mathrm{MgO}-\mathrm{ZrO}_{2}$ by aging, Trans. JIM, 1988, 29, 561-569.

23. Echigoya, J., Asano, W. and Yamaguchi, A., Microstructure of sputtered $\mathrm{CoFe}_{2} \mathrm{O}_{4}$ film, phys. stat. sol. (a), 2002, 191, 359-369. 